\title{
EVOLUÇÃO DOS PIGMENTOS DURANTE O AMADURECIMENTO DE MAMÃO 'SUNRISE SOLO' E 'GOLDEN'
}

\author{
MARCOS JOSÉ DE OLIVEIRA FONSECA ${ }^{2}$, NILTON ROCHA LEAL ${ }^{3}$, SÉRGIO AGOSTINHO CENCI ${ }^{2}$, \\ PAULO ROBERTO CECON ${ }^{4}$, RICARDO ENRIQUE BRESSAN-SMITH ${ }^{3}$, JOSÉ MAURO DE SOUZA BALBINO ${ }^{5}$
}

RESUMO - O objetivo deste estudo foi explicar as diferenças na coloração da polpa e da casca entre os frutos dos mamoeiros 'Sunrise Solo' e 'Golden', e desenvolver escalas de maturação visual. Os frutos foram colhidos em sete estádios de maturação, baseando-se no percentual de coloração amarela na casca, em pomar comercial localizado em Linhares-ES. O mamão ‘Golden' mostrouse difícil de classificar por meio de escala visual, devido a sua coloração mais clara. O mamão 'Sunrise Solo' possui teores mais elevados de clorofila total, $a$ e $b$, e reduzido teor de carotenóides totais, no primeiro estádio e em outros dois estádios $\left(4^{\circ}\right.$ e $6^{\circ}$ estádios de maturação). A mudança de cor foi mais evidente nesta cultivar. A relação entre clorofilas totais e carotenóides totais foi superior na cultivar Sunrise Solo até o sexto estádio. Por isso, recomenda-se cuidado no manuseio pós-colheita do mutante Golden, principalmente quanto ao ponto de colheita, por causa da dificuldade de distinção entre os estádios de maturação.

Termos para indexação: Clorofila, carotenóides, Carica papaya L., escala de maturação.

\section{PIGMENTS EVOLUTION DURING RIPENING OF PAPAYA CULTIVAR SUNRISE SOLO AND THE MUTANT GOLDEN}

\begin{abstract}
The objective of this study was to explain the peel and pulp differences between 'Sunrise Solo' papaya and its mutant 'Golden', and to develop maturation scales for the cultivars. Fruits were harvested from commercial farming located at Linhares-ES, Brazil, at seven different maturation stages based on the peel colour. It was difficult to classify the 'Golden' papaya through visual colour scale due to its lighter coloration. The 'Sunrise Solo' papaya had higher total chlorophyll and the $a$ and $b$ content. Thus, this cultivar has reduced carotenoids content on initial stage and in other two stages (4" and 6" maturation stages). Besides, the colour change was more evident in 'Sunrise Solo'. The total chlorophyll and carotenoid ratio was higher in 'Sunrise Solo' papaya up to the sixth stage. Thereby, it is recommended careful management for the mutant, specially in relation to the harvest point, due to the difficulty to distinguish among its maturation stages.
\end{abstract}

Index terms: Chlorophyll, carotenoid, Carica papaya L., Maturation scale.

\section{INTRODUÇÃO}

Apesar das limitações do uso da coloração externa como meio de se predizerem outras características relacionadas ao ponto de colheita ideal, essa é a característica rotineiramente utilizada para as cultivares de mamão comercializadas inclusive para o mercado externo (Bleinroth e Sigrist, 1995). Entretanto, com o surgimento da cultivar Golden, mutante que surgiu em lavoura da cultivar Sunrise Solo, o uso dessa característica tem trazido problemas para a correta classificação, uma vez que esse material apresenta coloração verde mais clara que a cultivar Sunrise Solo. Marin e Gomes (2000) descrevem, sucintamente, aquela cultivar como "acentuadamente aclorofilada". Bleinroth (1995) afirma que é muito importante que se conheça o ponto de colheita do mamão com exatidão para que, em seu amadurecimento, o aroma e o sabor se desenvolvam o melhor possível. Azzolini et al. (2004) verificaram, instrumentalmente, que goiabas 'Pedro Sato' colhidas no estádio 1 eram mais verdes que as colhidas nos estádios 2 e 3 , atribuindo essa diferença ao provável maior teor de clorofilas nas goiabas colhidas precocemente, e que as colhidas no estádio 3 possuíam qualidade superior àquelas colhidas no estádio 2 , que, por sua vez, foram consideradas superiores àquelas colhidas no estádio 1.

Segundo Bleinroth (1995), frutos da cultivar Solo não devem ser colhidos com menos de $11,5^{\circ}$ Brix, o que corresponde a $6 \%$ de coloração amarelada na casca. O nível máximo do teor de sólidos solúveis é observado quando $33 \%$ da superfície do fruto está amarela (Bleinroth, 1995). Akamine e Goo (1971) encontraram teor máximo de sólidos solúveis (14,5 Brix) em frutos de mamão 'Solo', no Havaí, com $80 \%$ de coloração amarela na casca. Para se alcançar esse índice, o fruto deveria ser colhido com, no mínimo, $33 \%$ de coloração amarela na casca. Malgarim et al. (2005) verificaram que as características físico-químicas da ameixa 'Amarelinha' foram superiores quando colhidas nos estádios M2 (25 a 50\% de pigmentação característica amarelo-avermelhada, medida pelo parâmetro ${ }^{\circ} \mathrm{h}$ - ângulo Hue) e M3 (mais que 50\% de pigmentação), em relação a ameixas colhidas mais verdes (M1até $25 \%$ de pigmentação).

\footnotetext{
1 (Trabalho 092-05). Recebido: 03-06-2005. Aceito para publicação:22-06-2007. Parte da Tese de Doutorado do primeiro autor

2 Engenheiro Agrônomo, D.Sc. Pesquisador da Embrapa Agroindústria de Alimentos. Av. das Américas, 29501 - Guaratiba CEP 23020-470, Rio de Janeiro-RJ, e-mail: mfonseca@ctaa.embrapa.br, cenci@ctaa.embrapa.br

${ }_{3}^{3} \mathrm{PhD}$, Professor da Universidade Estadual do Norte Fluminense - Centro de Ciências e Tecnologias Agropecuárias, e-mail: nilton@uenf.br, bressan@uenf.br

${ }^{4}$ D.Sc., Professor da Universidade Federal de Viçosa - Departamento de Informática, e-mail: cecon@dpi.ufv.br

${ }^{5}$ D.Sc., Pesquisador do Instituto Capixaba de Pesquisa Agropecuária e de Extensão Rural, e-mail: balbino@incaper.es.gov.br
} 
Os objetivos deste trabalho foram desenvolver escala de maturação visual dos mamões 'Sunrise Solo' e 'Golden', e realizar estudo comparativo dos pigmentos medidos na casca e na polpa das duas referidas cultivares.

\section{MATERIAL E MÉTODOS}

Em outubro de 1999, frutos de mamoeiro 'Sunrise Solo' e 'Golden' foram colhidos em pomar comercial da empresa GAIA Importação e Exportação Ltda., localizado em Linhares-ES. O clima da região apresenta temperaturas máximas entre 30 e $32^{\circ} \mathrm{C}$, temperaturas mínimas entre 15 e $18^{\circ} \mathrm{C}$ (Feitosa, 1986), e pluviosidade anual média de $1.183 \mathrm{~mm}$, com evapotranspiração potencial anual de $1.388 \mathrm{~mm}$ (Castro e Scárdua, 1985).

Foram amostrados frutos das cultivares 'Sunrise Solo' e 'Golden' colhidos aleatoriamente, nos estádios 1 (até $10 \%$ de coloração amarela na casca); 2 (10 a 25\% de coloração amarela na casca); 3 (26 a 40\% de coloração amarela na casca); 4 (41 a 55\% de coloração amarela de casca); 5 (56 a 70\% de coloração amarela de casca); 6 (71 a 85\% de coloração amarela de casca), e 7 (86 a 100\% de coloração amarela de casca), de acordo com escala de maturação desenvolvida por Balbino (1997) para a cultivar Sunrise Solo 72/12.

Os frutos de todos os estádios foram analisados no mesmo dia em que foram colhidos, no Laboratório de Fisiologia Vegetal, da INCAPER, em Linhares-ES, para as seguintes características: teor de clorofilas a, b e total, e carotenóides totais de casca, e carotenóides totais de polpa (2,0 g de casca - retiradas da região equatorial do fruto - ou de polpa foram macerados em acetona $80 \%$, adicionando-se um pouco de $\mathrm{CaCO}_{3}$ ). Após a filtração do macerado, completou-se o volume de extrato cetônico para 25 $\mathrm{mL}$, realizando-se leitura da solução em espectrofotômetro, a 470,0 $\mathrm{nm}, 646,8 \mathrm{~nm}$ e $663,2 \mathrm{~nm}$, e aplicando-se os valores nas equações desenvolvidas por Lichtenthaler (1987).

Os dados foram analisados por meio de análise de variância, sendo que as fontes de variação (efeitos de cultivar, estádio de maturação e sua interação) foram dispostas em esquema fatorial, num delineamento inteiramente casualizado. $\mathrm{O}$ número de repetições foi desigual (dez frutos nos estádios 3; 4 e 5, cinco frutos nos estádios $2 ; 6$ e 7, e seis frutos no estádio 1 da cultivar Sunrise Solo; cinco frutos nos estádios 1; 2; 3 e 4; 15 no estádio 5; 14 no estádio 6, e nove no estádio 7 da cultivar Golden), devido à disponibilidade de frutos em cada estádio no momento da colheita. As médias foram comparadas utilizando-se do teste $\mathrm{F}$ (suficiente para discernir diferença entre duas cultivares) e Tukey (para verificação de diferença entre estádio de maturação), adotando-se nível de $5 \%$ de probabilidade.

\section{RESULTADOS E DISCUSSÃO}

A diferença visual entre os estádios de mamão 'Sunrise Solo' foi evidente, podendo-se acompanhar a evolução do amadurecimento, que se iniciou da base do fruto em direção à região do pedúnculo (Figura 1). Outra observação é a formação nítida das estrias ou pintas na superfície do fruto, que orientam o produtor para o momento da colheita. Os estádios fisiológicos
2; 3 e 4 correspondem aos estádios de 1;2 e 3 pintas respectivamente, enquanto o estádio fisiológico 1 está correlacionado ao verde maduro, ou seja, momento em que o fruto está apto a ser colhido e amadurecer naturalmente, porém o risco de se colher e o mesmo não amadurecer é grande. O estádio 6 corresponde ao fruto maduro para consumo, e o estádio 7 corresponde ao sobreamadurecimento, com sua coloração de casca completamente amarela. Na Figura 1, não se observa a mesma clareza para a distinção entre os estádios de maturação da cultivar Golden, como ocorre para 'Sunrise Solo'. Pode-se observar padrão semelhante, embora menos evidente, de amadurecimento da base para o pedúnculo, e da cavidade interna em direção à casca.

Em relação à polpa do mamão 'Sunrise Solo', pode-se constatar o amadurecimento radial a partir da cavidade interna em direção à casca, comparando-se os estádios 1 e 2 . Os estádios 3; 4 e 5 confirmam essa evolução em direção à casca, que se torna mais fina durante o samadurecimento. Nos estádios 6 e 7, pode-se observar que a polpa está completamente madura, sendo que, no último estádio, pode-se verificar região apresentando desintegração da polpa. Da mesma forma que o mamão 'Sunrise Solo' no estádio 7, o mamão 'Golden' apresentou parte da polpa com aspecto geleificado, característica de fruto senescente ou sobremaduro.

Observa-se, na Tabela 1, a redução nos teores de clorofila total para mamão 'Sunrise Solo' e 'Golden', e que diferenças significativas entre as cultivares ocorreram até o estádio 6 , sempre menores em Golden, igualando-se no estádio 7, momento em que os frutos estavam sobremaduros, com coloração externa totalmente amarelada. Os carotenóides de casca apresentam incremento em ambas as cultivares, porém de forma mais intensa na cultivar Sunrise Solo. Isto pode ser explicado pelo fato de o mamão 'Golden' possuir teores de carotenóides na casca superiores nos estádios 1; 4 e 6, em relação ao mamão 'Sunrise Solo’, sendo que estes se elevaram, significativamente, em mamão 'Golden', apenas nos estádios 6 e 7.

A relação entre clorofila total na casca e carotenóides totais na casca fornece a informação do balanço entre os pigmentos, e sua observação ao longo dos diferentes estádios de amadurecimento propicia informações que caracterizam o mamão 'Golden' como mutante de pigmentação do mamão 'Sunrise Solo' (Tabela 1). Entre os estádios 1 e 6, o mamão 'Sunrise Solo' apresenta as maiores relações, que somente se igualam no estádio 7, momento em que a influência da clorofila na relação é mínima. Outra observação é que ocorre decréscimo gradual entre os estádios de amadurecimento da cultivar Sunrise Solo, enquanto o decréscimo é menos acentuado na cultivar Golden. Os teores de clorofila $a$ e $b$ são inferiores na cultivar Golden, em todos os estádios de amadurecimento, com exceção do estádio 6 para clorofila $a$ e 7 para clorofila $b$, quando, em ambas as cultivares ocorrem teores reduzidos (Tabela 2). Observa-se, em mamão 'Sunrise Solo', que, embora ocorra o decréscimo gradual dos teores de clorofila $a$, somente após o estádio 4, estas diferenças são significativas. Em mamão 'Golden', as diferenças significativas ocorrem a partir do estádio 3 . A elevação desses teores, entre os estádios 6 e 7, não é significativa e, nestes 
estádios, é que se observam os menores teores de clorofila $a$ para as cultivares de mamão. Nos frutos da cultivar Sunrise Solo, observa-se redução dos teores de clorofila $b$ a partir do estádio 5 , pois, entre os estádios $1 ; 2$ e 3, e entre os estádios $2 ; 3$ e 4, não se verificam diferenças significativas (Tabela 2). Os menores teores podem ser observados no estádio 7. A cultivar Golden apresenta diferenças menos evidentes ainda, uma vez que não se observam diferenças entre os estádios 1; 2 e 3, e entre os estádios 4; 5; 6 e 7, sendo que também não são observadas diferenças entre os estádios 3; 4 e 5 (Tabela 2). Essas observações constatam que o padrão de degradação da clorofila $b$ é menos intenso que o da clorofila $a$, em mamão 'Golden'. Observou-se a elevação dos teores da clorofila $a$, em ambas as cultivares do estádio 6 para o 7. Isto é explicado pelo fato de a clorofila $b$ ser convertida em clorofila $a$, pela substituição do grupamento aldeído pelo grupamento metila no segundo anel pirrólico (Salisbury e Ross, 1992; De las Rivas, 2000), para entrar em rota degradativa (Matile et al., 1996). A comprovação do fato é que o teor de clorofila $b$ se reduz nesta passagem de estádio, em ambos os casos, e mais intensamente em mamão 'Sunrise Solo'.

Ocorrem flutuações nos teores de carotenóides na polpa do mamão 'Golden' que promovem diferenças significativas opostas em dois momentos (Tabela 2). No estádio 2, o 'Golden' apresenta teores maiores, e menores no estádio 4, em relação a 'Sunrise Solo'.

Outra abordagem importante é a das relações de aumento e redução dos teores e relação dentro de cada cultivar. Na Tabela 1, pode-se observar que o teor de clorofila total em mamão 'Sunrise Solo' se apresenta decrescente a partir do estádio 1 até o estádio 7. Na Tabela 2, pode-se observar tendência semelhantes para os componentes clorofila $a$ e clorofila $b$. Outra característica importante no amadurecimento do mamão 'Sunrise Solo' é a redução da relação entre clorofila total e carotenóides totais na casca, de 7,367 para 0,307, devido à já referida degradação de clorofila e à biossíntese dos carotenóides, que têm seus teores elevados a partir de $26,981 \mathrm{mg}$ (g polpa) $)^{-1}$, no estádio 1 , até 84,914 $\mathrm{mg}(\mathrm{g} \text { polpa })^{-1}$, no estádio 7 (Tabela 1). Este incremento é de 3,15 vezes, enquanto a redução do teor de clorofila total é da ordem de 7,30, comprovando que a última característica é a maior responsável pela redução dos valores da relação entre clorofila total e carotenóides totais na casca e, conseqüentemente, da mudança de cor do mamão 'Sunrise Solo'. A última característica descrita para o mamão 'Sunrise Solo' é o teor de carotenóides totais de polpa que, da mesma forma que na casca, têm seus teores elevados entre os estádios 1 e 7 , incremento este ainda maior, da ordem de 4,19 vezes (Tabela 2). Em mamão 'Golden', observa-se, entre os estádios 1 e 2 , incrementos nos teores de clorofila total (Tabela 1), nos teores de clorofila $a$ e de clorofila $b$ (Tabela 2), e decréscimo nos teores de carotenóides totais na casca (Tabela 1) e conseqüente elevação da relação entre clorofila total e carotenóides totais na casca $(2,433$ para 2,827$)$ (Tabela 1$)$, fato que não ocorre em mamão 'Sunrise Solo'. Porém, a partir deste estádio, podem ser observadas as esperadas tendências de decréscimo nos teores de clorofila e da relação entre clorofila e carotenóides totais na casca, e elevação dos teores de carotenóides na polpa e na casca. Yamanishi et al. (2005) verificaram haver correlação entre os valores médios de clorofilas $a$ e $b$, que decresceram ao longo do desenvolvimento do mamão Tainung 1. Os autores constataram aumento médio do teor de clorofila a, entre 84 e 126 dias após a frutificação efetiva (DAFE), e pico de teor de clorofila $b$ no $126^{\circ} \mathrm{DAFE}$, momento que consideraram adequado para a colheita dessa cultivar.

O decréscimo da relação entre os teores de clorofila total e de carotenóides totais, em mamão 'Golden', também se deve, principalmente, à maior redução dos teores de clorofila $(5,42$ vezes) comparada ao pequeno aumento no teor de carotenóides (0,59 vez). A diferença entre os dois fenômenos é de quase 10 vezes, enquanto em mamão 'Sunrise Solo' se observa diferença de, aproximadamente, duas vezes. Isto indica que a dinâmica de síntese e degradação de pigmentos na casca das cultivares é diferente e pode explicar a dificuldade de se caracterizarem estádios de maturação em mamão 'Golden'. Ocorrem fatores aparentemente inexplicáveis, como a elevação das clorofilas e a redução dos carotenóides na casca, mesmo que pequenas, entre os estádios 1 e 2, quando se esperava o contrário. Essas variações ocorrem, pelo menos em parte, devido ao fato de que, em cada avaliação ou estádio, serem usados frutos diferentes, pois a metodologia é destrutiva, ou seja, o processo de maturação não é acompanhado no mesmo fruto. Na Tabela 2, observa-se, em mamão 'Golden', que o teor de carotenóides de polpa se eleva do estádio 1 para o 2, para daí decrescer até o estádio 4. Ocorre elevação abrupta no estádio 5, para ocorrer nova redução, embora menor, até o estádio 7. De forma geral, ocorre a elevação dos

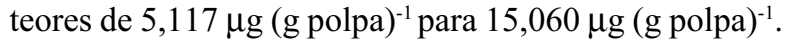

A observação da relação entre os pigmentos demonstra, consistentemente, a diferenciação entre as cultivares, pois os menores valores obtidos pelo mamão 'Golden', até o sexto estádio, justificam a dificuldade em se identificarem, claramente, as mudanças de estádio que ocorrem como conseqüência da degradação da clorofila e da biossíntese de carotenóides. A coloração menos intensa promovida pelo menor teor de clorofila é, ainda, mascarada pelos teores iniciais mais elevados dos carotenóides.

Anteriormente, Balbino (1997) havia estabelecido escala visual para mamão 'Sunrise Solo 72/12'. Bleinroth e Sigrist (1989) apresentam escala de maturação visual do mamão constando de 8 estádios, porém não houve especificação de cultivar, talvez pelo fato de as cultivares comerciais naquela época não apresentarem a disparidade de coloração de casca existente entre o mamão ‘Golden' e os demais.

Embora seja difícil recomendar alguma alternativa para a classificação do mamão 'Golden', pode-se afirmar que o índice de variação de cor de casca como referência do estádio de maturação não foi característica adequada para classificar o mamão 'Golden', diferentemente do que se observou para 'Sunrise Solo', tradicionalmente classificado de acordo com as nítidas estrias amarelas que se desenvolvem na base dos frutos. Essa suposta distinção pode promover problemas de classificação, possibilitando a inclusão de frutos mais maduros em lotes contendo frutos menos desenvolvidos fisiologicamente. A má classificação dos frutos dessa cultivar pode provocar desuniformidade em caixas e forçar o amadurecimento prévio de 
frutos, encurtando a vida pós-colheita. Esse problema já foi constatado por produtores e exportadores do norte do Espírito Santo, Brasil.

TABELA 1 - Valores médios de teor total de clorofilas (Clt), de carotenóides totais na casca (Cc) e da relação entre teor total de clorofila e carotenóides totais na casca $(\mathrm{Clt} / \mathrm{Cc})$ em mamões 'Sunrise Solo' e 'Golden', nos diferentes estádios de maturacão.

\begin{tabular}{|c|c|c|c|c|c|c|}
\hline \multirow[t]{2}{*}{ Escala } & \multicolumn{2}{|c|}{ Clt $\left[\mu \mathrm{g}(\mathrm{g} \text { casca })^{-1}\right]$} & \multicolumn{2}{|c|}{$\mathrm{Cc}\left[\mu \mathrm{g}\left(\mathrm{g}_{\mathrm{casca}}\right)^{-1}\right]$} & \multicolumn{2}{|c|}{$\mathrm{Clt} / \mathrm{Cc}$} \\
\hline & 'Sunrise Solo' & 'Golden' & 'Sunrise Solo' & 'Golden' & 'Sunrise Solo' & 'Golden' \\
\hline 1 & $192,358 \mathrm{Aa}$ & $104,599 \mathrm{ABb}$ & $26,981 \mathrm{Db}$ & $43,346 \mathrm{Ba}$ & 7,37Aa & $2,43 \mathrm{Ab}$ \\
\hline 2 & $174,736 \mathrm{ABa}$ & $113,592 \mathrm{Ab}$ & $31,654 \mathrm{CDa}$ & $40,306 \mathrm{Ba}$ & $5,72 \mathrm{ABa}$ & $2,83 \mathrm{Ab}$ \\
\hline 3 & $164,079 \mathrm{ABa}$ & $67,813 \mathrm{BCb}$ & $37,784 \mathrm{CDa}$ & $47,791 \mathrm{Ba}$ & $4,43 \mathrm{BCa}$ & $1,47 \mathrm{ABb}$ \\
\hline 4 & $143,751 \mathrm{Ba}$ & $58,128 \mathrm{Cb}$ & $40,446 \mathrm{BCDb}$ & $51,289 \mathrm{Ba}$ & $3,64 \mathrm{CDa}$ & $1,17 \mathrm{ABb}$ \\
\hline 5 & $97,679 \mathrm{Ca}$ & $41,573 \mathrm{CDb}$ & $52,116 \mathrm{Ba}$ & $55,227 \mathrm{Ba}$ & $1,91 \mathrm{Ea}$ & $0,77 \mathrm{Bb}$ \\
\hline 6 & $70,770 \mathrm{Ca}$ & $19,465 \mathrm{Db}$ & $46,761 \mathrm{BCb}$ & $76,402 \mathrm{Aa}$ & $2,46 \mathrm{DEa}$ & $0,28 \mathrm{Bb}$ \\
\hline 7 & $26,365 \mathrm{Da}$ & $19,287 \mathrm{Da}$ & $84,914 \mathrm{Aa}$ & $73,906 \mathrm{Aa}$ & $0,31 \mathrm{Fa}$ & $0,25 \mathrm{Ba}$ \\
\hline
\end{tabular}

* Médias seguidas de pelo menos uma mesma letra maiúscula na coluna e minúscula na linha, para cada característica, não diferem entre si, a 5\% de probabilidade, pelo teste Tukey

TABELA 2 - Valores médios de teor de clorofila $a(\mathrm{Cl} a)$, de teor de clorofila $b(\mathrm{Cl} b)$ na casca e de carotenóides totais na polpa $(\mathrm{Cp})$ em mamões 'Sunrise Solo' e 'Golden', nos diferentes estádios de maturação.

\begin{tabular}{|c|c|c|c|c|c|c|}
\hline \multirow[t]{2}{*}{ Escala } & \multicolumn{2}{|c|}{$\mathrm{Cl} a\left[\mu \mathrm{g}\left(\mathrm{g}_{\mathrm{casca}}\right)^{-1}\right]$} & \multicolumn{2}{|c|}{$\mathrm{Cl} b\left[\mu \mathrm{g}(\mathrm{g} \text { casca })^{-1}\right]$} & \multicolumn{2}{|c|}{$\mathrm{Cp}\left[\mu \mathrm{g}(\mathrm{g} \text { polpa })^{-1}\right]$} \\
\hline & 'Sunrise Solo' & 'Golden' & 'Sunrise Solo' & 'Golden' & 'Sunrise Solo' & 'Golden' \\
\hline 1 & 57,059Aa & $33,997 \mathrm{Ab}$ & $135,299 \mathrm{Aa}$ & $73,110 \mathrm{ABb}$ & $3,520 \mathrm{Da}$ & $5,117 \mathrm{Ca}$ \\
\hline 2 & $52,623 \mathrm{ABa}$ & $31,488 \mathrm{Ab}$ & $122,113 \mathrm{ABa}$ & $79,595 \mathrm{Ab}$ & $5,526 \mathrm{CDb}$ & $12,198 \mathrm{ABCa}$ \\
\hline 3 & $49,296 \mathrm{ABa}$ & $17,441 \mathrm{Bb}$ & $114,783 \mathrm{ABa}$ & $50,373 \mathrm{ABCb}$ & $8,190 \mathrm{BCDa}$ & $9,209 \mathrm{BCa}$ \\
\hline 4 & $43,512 \mathrm{Ba}$ & $14,105 \mathrm{Bb}$ & $100,239 \mathrm{Ba}$ & $44,024 \mathrm{BCDb}$ & $15,658 \mathrm{Aa}$ & $6,715 \mathrm{Cb}$ \\
\hline 5 & $28,732 \mathrm{Ca}$ & $8,573 \mathrm{BCb}$ & $68,948 \mathrm{Ca}$ & $32,999 \mathrm{CDb}$ & $16,203 \mathrm{Aa}$ & $14,379 \mathrm{ABa}$ \\
\hline 6 & $4,774 \mathrm{Da}$ & $0,126 \mathrm{Da}$ & $65,996 \mathrm{Ca}$ & $19,590 \mathrm{Db}$ & $13,477 \mathrm{ABCa}$ & $17,693 \mathrm{Aa}$ \\
\hline 7 & $12,066 \mathrm{Da}$ & $1,170 \mathrm{CDb}$ & $14,298 \mathrm{Da}$ & $18,116 \mathrm{Da}$ & $14,740 \mathrm{ABa}$ & $14,594 \mathrm{ABa}$ \\
\hline
\end{tabular}

* Médias seguidas de pelo menos uma mesma letra maiúscula na coluna e minúscula na linha, para cada característica, não diferem entre si, a 5\% de probabilidade, pelo teste Tukey.

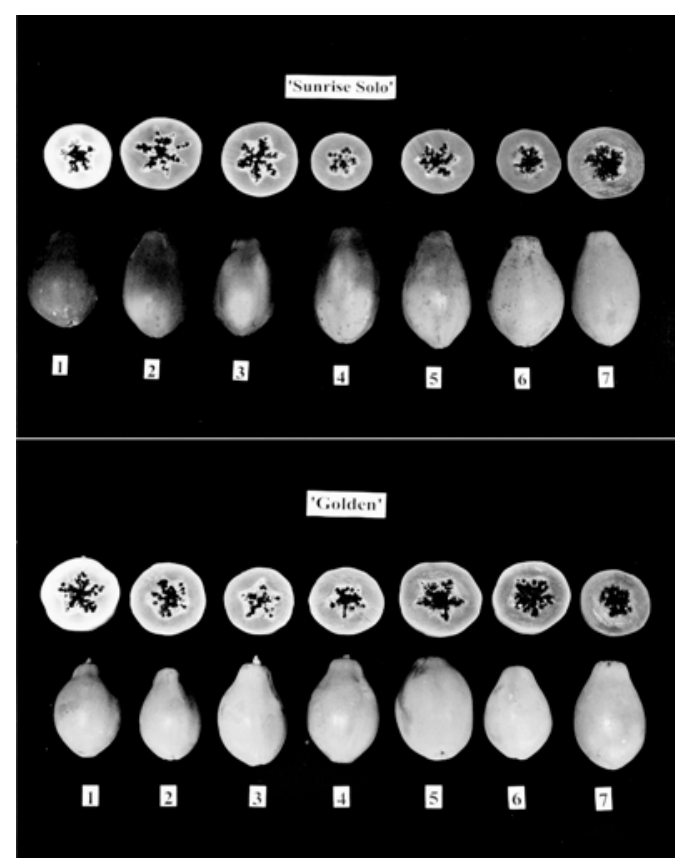

FIGURA1 - Escala visual de maturação de frutos de mamoeiro das cultivares 'Sunrise Solo' e 'Golden'.

\section{CONCLUSÕES}

1-O mamão 'Sunrise Solo' apresentou melhor discriminação entre os estádios de maturação, em relação ao mamão 'Golden', nos seis primeiros estádios de maturação.

2 - Houve dificuldade para a classificação da cultivar Golden, devido à reduzida relação clorofilas/carotenóides totais na casca.

\section{AGRADECIMENTOS}

Nossos sinceros agradecimentos para a Empresa GAIA importação e Exportação, pelo fornecimento dos frutos, para a Fundação Estadual do Norte Fluminense (FENORTE), pela bolsa de estudos concedida, e para o INCAPER, em especial para a Pesquisadora Adelaide de Fátima Santana da Costa, pela assistência de campo. 


\section{REFERÊNCIAS}

AKAMINE, E.K.; GOO, T. Relationship between surface color development and total soluble solids in papaya. HortScience, Alexandria, v.6, n.6, p.567-568, 1971.

AZZOLINI, M., JACOMINO, A.P., SPOTO, M.H.F. Estádios de maturação e qualidade pós-colheita de goiabas 'Pedro Sato'. Revista Brasileira de Fruticultura, Jaboticabal, v.26, n.1, p.29$31,2004$.

BALBINO, J.M.S. Efeitos de hidrotermia, refrigeração e ethephon na qualidade pós-colheita do mamão (Carica papaya L.). 1997. $104 \mathrm{f}$. Tese (Doutorado em Fisiologia Vegetal) Universidade Federal de Viçosa, Viçosa, 1997.

BLEINROTH, E.W.; SIGRIST, J.M.M. II - Matéria-prima. In: ITAL Mamão: cultura, matéria-prima, processamento e aspectos econômicos. Campinas: ITAL, 1995. p.179-254.

BLEINROTH, E.W. Determinação do ponto de colheita. In: Gayet, J.P., Bleinroth, E.P., Matallo, M., Garcia, E.E.C., Garcia, A.E., Ardito, E.F.G., Bordin, M.R. (Ed.). Mamão para exportação: procedimentos de colheita e pós-colheita. Brasília: EMBRAPA-SPI, 1995. p.1025 .

CASTRO, L.L.F. DE; SCÁRDUA, J.A. Estimativa da necessidade potencial de irrigação para o Estado do Espírito Santo. Cariacica: EMCAPA, 1985. 87 p. (Documentos, 22)

DE LAS RIVAS, J. La luz y el aparato fotossintético. In: AZCÓNBIETO, J.; TALÓN, M. (Ed.). Fundamentos de fisiología vegetal. Barcelona: Edicions Universitat de Barcelona, 2000. p.131-153.
FEITOSA, L.R. Carta agroclimática do Espírito Santo. Vitória: SEAG-EMCAPA, 1986. Mapa colorido, Escala: 1:400.000.

LICHTENTHALER, H.K. Chlorophylls and carotenoids: pigments of photosynthetic biomembranes. Methods in Enzymology, San Diego, v.148, n.22, p.346-382, 1987.

MALGARIM, M.B., CANTILLANO, F.R.F., TREPTOW, R.O., SOUZA, E.L., COUTINHO, E.F. Estádios de maturação e variação da temperatura de armazenamento na qualidade pós-colheita de ameixas cv. Amarelinha. Revista Brasileira de Fruticultura, Jaboticabal, v.27, n.1, p.29-35, 2005.

MARIN, S.L.D.; GOMES, J.A. Cultura do mamão. In: SEMANA INTERNACIONAL DE FRUTICULTURA E AGROINDÚSTRIA, 7., 2000, Fortaleza: Instituto FRUTAL, 2000. 50p.

MATILE, P.; HORTENSTEINER, S.; THOMAS, H.; KRAUTLER, B. Chlorophyll breakdown in senescent leaves. Plant Physiology, Oxford, v.112, n.4, p.1403-1409, 1996.

SALISBURY, F.B.; ROSS, C.W. Plant physiology. Belmont: Wadsworth Publishing Company, 1992. 682p.

YAMANISHI, O.K., FAGUNDES, G.R., MACHADO FILHO, J.A., FALCÃO, J.V., MIRANDA, S.P. Comportamento da maturação de mamão Tainung 1 cultivado em Brasília-DF. Revista Brasileira de Fruticultura, Jaboticabal, v.27, n.2, p.314-316, 2005. 